\title{
Excelencia e innovación en las tecnologías de la comunicación y de la imagen: Reconstrucción de un debate entre Wiesing, Levinson, Crowther y Seel
}

\author{
Carlos Ortiz de Landázuri, Universidad de Navarra, Navarra, España
}

Resumen: Los criterios de excelencia e innovación a la hora de valorar las tecnologías de la comunicación se ven afectados por un gran número de factores, pero al final hay uno que prima sobre todos los demás: la calidad de la imágenes utilizadas, como sucede con National Geographic y Walt Disney, dos empresas de comunicación que han sido determinantes a la hora de fijar los criterios estándar de excelencia e innovación. En este contexto se reconstruye el debate contemporáneo entre Wiesing, Levinson, Crowther y Seel acerca de los criterios de excelencia e innovación usados a la hora de valorar la calidad de las imágenes virtuales mediáticas por parte de las tecnologías de la comunicación, teniendo en cuenta su cuádruple dimensión genético-retroductiva, simbólica, contextual y estrictamente escénica.

Palabras Clave: Tecnologias de comunicacion, Calidad de las imagenes, Comunicacion, Criterios de excelencia

Abstract: The criteria of excellence and innovation concerning the technologies of the communication that see affected by a big number of factors, but at the end there is one that prevails on all the other: The quality of the images used, as it occurs with National Geographic and Walt Disney, two companies of communication that have been leaders concerning the fixation of the standard criteria of excellence and innovation. In this context reconstructs the contemporary debate between Wiesing, Levinson, Crowther and Seel about the criteria of excellence and innovation used concerning the assessment of the quality of the mediated virtual images by part of the technologies of the communication, taking into account his four genetic dimensions, to know: retroductive, symbolic, contextual and strictly scenic.

Keywords: Innovation, image, excellence, communication

\section{Wiesing, 2006: la dimensión genético-retroductiva de las imágenes virtuales mediáticas}

$\mathrm{L}$

AMBERT WIESING EN 2006, en Presencias artificiales. Estudios sobre la filosofia de las imágenes mediáticas (Wiesing, 2006), aborda directamente la paradoja ficcionalista de la realidad virtual, a saber (Taylor, 2006): si el reconocimiento del carácter virtual de una imagen mediática exige asignarle un modo de ser artificial en sí mismo ficcional respecto de la realidad en su caso representada, ¿entonces cómo las ciencias de la imagen podrán evitar la aparición de un creciente ilusionismo en sí mismo ficticio, dando a su vez lugar a una creciente manipulación por parte del conjunto de los medios de comunicación? (Gibson, 2007). Para mostrar cómo es posible evitar una situación tan comprometida para la teoría de la imagen, lleva a cabo un análisis genético-retroductivo

Revista Internacional de Ciencias Humanas

Volumen 1, Número 2, http://lascienciashumanas.com, ISSN 2530-4526

(C) Global Knowledge Academics, Carlos Ortiz de Landázuri, Todos los Derechos Reservados

Permisos: soporte@gkacademics.com

Republicado de Revista Internacional de Ciencias Humanas 1(2), 2012 (pp. 135-148) 
de los cuatro niveles posibles de la realidad virtual, a fin de mostrar como un análisis interno de este tipo de imágenes nos permitiría evitar las paradojas que ellas mismas podrían producir (Goldstein, 2007), a saber:

1. Los proto-elementos virtuales básicos recíprocamente interaccionados que hacen a su vez posible una imagen mediática, separando a su vez tres aspectos (Schweidler, 2007): a) la imagen virtual en sí misma considerada; b) el objeto sensible o soporte virtual al que la imagen se aplica; y c) el significado antropológico-cultural igualmente virtual otorgado a esa imagen, evitando así el círculo hermenéutico que a su vez se establece entre aquellas otras dos fases previas (Becker, Orth, 2005).

2. La triple realidad virtual propiamente dicha, resultante a su vez de la anterior transformación acaecida en los anteriores proto-elementos para dar lugar a una imagen mediática o signo icónico, con capacidad incluso de representarse a sí mismos, mediante tres pasos (Eisentein, 2006): a) se toma el signo como soporte virtual de sí mismo; b) se toma el signo como un mero transmisor virtual de una imagen mediática; y c) se otorga al signo el valorantropológico-cultural, que a su vez está sobreentendido tras la simple evocación de aquellos objetos sensibles e imágenes que le sirven de soporte (Spivey, 2006).

3. La triple presencia artificial sobrevenida a los tres anteriores tipos de realidad virtual mediante una ulterior reinterpretación por parte del intérprete, a saber (Seel, 2006): a) la presencia artificial o virtual cuando aquellas ilusiones subjetivas se reinterpretan desde la propia fantasía; b) la presencia mediática o compartida cuando aquellas mismas ilusiones se reinterpretan desde la transmisión de una determinada tradición; c) la presencia intencional de un significado antropológico-cultural cuando aquellas imágenes se reinterpretan desde un conjunto aún más básico de actividades colectivas compartidas (Speranza, 2006).

4. Finalmente, el triple tipo de presencias tecnológicas o mediáticas generadas específicamente por los medios de comunicación social, dando a su vez lugar a un creciente paralelismo entre tres niveles de opinión pública, a saber (Bollini, 2007): a) los procesos psicológicos de formación de aquel tipo de ilusión subjetiva con ayuda de la fantasía en la que se fundan los procesos de imitación artística y cultural; b) los procesos cognitivos y conductuales que a su vez exigen compartir una actividad común, basada en una tradición, pero que ahora estaría reforzada también por la consabida comunicación de masas (Scheeler, 2006); c) los ulteriores procesos tecnológico-culturales que permiten incrementar hasta límites insospechados las posibilidades de compartir una misma realidad virtual, ya tengan un origen de tipo psicológico o simplemente conductual y cognitivo (Farber, 2007). A este respecto ahora se pretende justificar la peculiar transparencia y autorreferencialidad que este nuevo tipo de presencias tecnológicas o virtuales mediante distintos procesos fenomenológicos y semióticos de producción y de convalidación de imágenes propios del mundo de la imaginación, completando así la teoría de la comunicación de McLuhan con los análisis fenomenológicos de Husserl, aunque sin llegar a constituir ya un obstáculo, sino más bien una ayuda (Kulvicki, 2006).

Para concluir una reflexión crítica (Lackey, Sosa, 2006). Sin duda Wiesing prolonga la tesis de MacLuham acerca de que "el mensaje es el medio" tratando de mostrar como una mejor comprensión de este tipo de presencias tecnológicas o virtuales, podría terminar redundando 
en una mejora de los criterios de excelencia e innovación de los propios medios de comunicación de masas. A este respecto los ejemplos ya mencionados de la calidad de las imágenes difundidas por National Geographic y Walt Disney podrían ser un ejemplo paradigmático de este tipo de criterios. De todos modos ahora se considera necesario prologar de un modo más exhaustivo este tipo análisis a fin de poder exigir a los proto-elementos y a las distintas fases de proceso que las han hecho posibles un mayor respecto de los criterios de transpa-rencia y autorreferencialidad. Sólo así se podría exigir a este tipo de mediaciones tecnológicas una mejor justificación de la calidad virtual en cada caso exigida, prolongando a este respecto algunas sugerencias de Husserl (Budd, 2008). De todos modos a lo largo del debate sobre los criterios de excelencia e innovación de las imágenes mediáticas y los medios de comunicación no sólo se tuvo que tener en cuenta la dimensión virtual de los signos, sino también otras, como fueron la dimensión simbólica, contextual o su escenificación (Graham, 2007). Veámoslas.

\section{Levinson, 2006: la dimensión simbólica de las imágenes mediáticas}

Jerrold Levinson en 2006, en Contemplando el arte. Ensayos de Estética (Levinson, 2006), ha puesto de manifiesto como la mejor comprensión por parte de la cultura mediática contemporánea del uso virtual dado a las imágenes visuales debería también tener en cuenta su creciente poder transfigurador simbólico de su inicial significado simplemente vulgar u ordinario. En su opinión, esta es la conclusión adecuada que debería haber sacado el arte contemporáneo y las ciencias de la imagen posteriores a 1950 ante la formulación de la anterior paradoja de los artificios ilusionistas. En efecto, ya entonces se atribuyó a este tipo de imágenes virtuales una verosimilitud en sí misma ficticia, dada la infinita distancia existe entre un simple artefacto mimético respecto de la realidad representada, cuando la conclusión que habría que haber sacado es muy distinta, a saber (Everaert-Desmedt, 2006): tomar la aparición de la anterior paradoja de los artificios ilusionistas como un simple reconocimiento del alto grado de verosimilitud que también se les puede asignar a las meras ficciones virtuales sobrevenidas, con tal de cumplir una condición: poder justificar el tipo de artificios de simulación o de convención usados en cada caso para lograr tal fin, a pesar de tampoco poder atribuir a cada artificio ilusionista usado un grado de verosimilitud prefijado de antemano (Varnedoe, 2006).

En su opinión, Danton y Goodman ya advirtieron el creciente poder 'transfigurador' del sentido ordinario inicialmente otorgado por la fantasía a un objeto vulgar; por ejemplo, los 'ready-made' de Duchamp se podían transformar en auténticas obras de arte, a pesar de no servirse de los peculiares juegos del lenguaje y artificios ilusionistas descritos hasta entonces por Nelson Goodman, o antes por Wittgenstein. En su lugar Duchamp habría llamado la atención sobre un artificio muy sencillo usado con profusión por los medios de comunicación, pero que hasta entonces se había tenido poco en cuenta (Wollaeger, 2007): justificar el posible efecto ilusionista de una imagen virtual en virtud de un tipo de artificios meramente reiterativos de tipo mimético con capacidad de transfigurar el significado vulgar de aquel objeto natural para darle un significado mucho más excelso. Hasta el punto que el objeto vulgar podía elevarse a la condición de obra de arte, si sus potenciales destinatarios pasaban a atri buirle el rango de una realidad virtual compartida, con el tipo de etiqueta o denominación que en cada caso se estimase oportuna. De este modo se podría asignar a objetos aparentemente vulgares un valor artístico o comunicativo verdaderamente extraordinario, ampliando 
enormemente las posibilidades de la creatividad artística o de la simple comunicación social, como de hecho ocurrió en el mundo de la creatividad artística y virtual posterior a 1950 (Gower, 2007).

Según Levinson, es posible incrementar aún más el "poder transfigurador” de la imagen virtual mediática siempre que reúna un conjunto de requisitos o rasgos estéticos muy precisos. Por ejemplo, debe poder distinguir su significado vulgar o natural respecto al significado simbólico-virtual que de un modo inesperado le puede sobrevenir; por ejemplo, cuando es objeto de un artificio de tipo ilusionista. Especialmente así ocurre en el caso de las obras de arte e imágenes virtuales donde el descubrimiento histórico de determinados artificios ilusionistas habría permitido atribuirles una creciente verosimilitud en el modo de identificar los sentimientos humanos, como ahora se ejemplifica a través de numerosos ejemplos, especialmente con el peculiar poder evocador del lenguaje musical, ya se trate de la pintura o de las artes figurativas en general (Green, 2007). Pero algo similar podría afirmarse de los medios de comunicación, donde la mera repetición mimética de una imagen acaba otorgándole un grado de verosimilitud muy superior a la que inicialmente pudiera tener, de modo el final la imagen puede acabar alcanzando un significado simbólico-virtual que inicialmente no tenía. Las imágenes de National Geographic acaban simbolizando el máximo respeto con el medio ambiente, como las de Wald Disney simbolizan el ideal de máxima adaptación a la fantasía infantil, aunque en ambos casos se trate de una sobrevaloración que en gran parte está injustificada. Para justificar estas conclusiones se dan siete pasos:

1. Se utiliza la anterior paradoja ficcionalista de los artificios ilusionistas para justificar la peculiar génesis artística de toda imagen virtual, destacando a su vez cuatro puntos: a) todo arte ilusionista se remite de un modo inevitable a una imagen virtual mediática ordinaria, que en sí misma no tiene mayores pretensiones ilusionistas; b) la estricta separación entre artefactos sin pretensiones ilusionistas y las obras de arte que si las tienen, a pesar de recurrir en ambos casos a imágenes en sí mismas ordinarias (Baecker, $2005)$; c) las emociones como elemento válido que permite distinguir el carácter en sí mismo ilusionista de las manifestaciones artísticas virtuales, a diferencia de lo que ocurre con las que no tienen este tipo de pretensiones; d) el debate acerca del tipo de artificios figurativos e simbolistas que podrían ser usados por la creatividad simbolista con una finalidad artística o meramente virtual, polemizando sobre su carácter inventado o históricamente dado, como planteó Elster (Koselleck, 2006);

2. Destaca siete cuestiones de los artificios ilusionistas utilizados en común por la música y otras artes: la capacidad de ilusionar y de expresar emociones a través de los sonidos, los gestos o el espacio (Kivy, 2007); la sonoridad como condición inherente a la expresividad musical; las posibilidades y las limitaciones hipotéticas de una música meramente visual; la música como narrativa y como drama; el peculiar carácter narrativo de la música cinematográfica; la evaluación de los artificios simbolistas musicales; el papel de la teoría musical; la razón de ser de los emotivos escalofríos musicales ( $\mathrm{O}^{\prime}$ Callaghan, 2007);

3. Se justifica el papel habitualmente asignado a los artificios simbolistas en las artes figurativas pictóricas, destacando dos problemas: a) la polémica con Wollhein y Bud sobre la prioridad que ya Gombrich otorgó al 'ver-en' ilusionista ('trompe-oeil' o 'ver proyectivo') respecto de la simple visión a secas o vulgar de la tabla en sí, como un mero artefacto; b) la delimitación del arte simbolista figurativo respecto de dos extremos 
igualmente opuestos: el arte erótico, por un lado, y la pornografía o fotografía, por otro (Jäger, 2006);

4. Se analizan los efectos simbolista en la narrativa literaria a través de tres pasos: a) la separación entre la interpretación de los hechos narrados respecto de la explicación de la intención con que se hicieron (Barthes, 2007); b) el posible sentido de la metáfora y de la paráfrasis en la narración literaria y en el simbolismo pictórico o musical, siguiendo a Davidson y Wittgenstein; c) finalmente, el debate sobre la doble intencionalidad hipotética de una obra de arte, según se tome el lienzo como un simple hecho o como un soporte capaz de reflejar las intenciones virtuales de su autor (Gaut, 2007);

5. Se localizan las tres dimensiones estéticas inherentes a cualquier obra de arte: a) la fuerza o sensibilidadestética en virtud del grado de verosimilitud alcanzado por los artificios ilusionistas utilizados en cada caso; b) se conciben las propiedades artísticas como un resultado imitativo de determinados procesos histórico-culturales altamente sofisticados; c) Se justifica la dimensión simbólica que pueden acabar alcanzando en razón de su capacidad de hacer las veces de la realidad así descrita (Ameriks, Stolzenberg, 2007);

6. Se justifican dos presupuestos metafísicos y psicológicos de la teoría del arte, como son la psicología estética ilusionista de Shopenhauer y los criterios del gusto artístico imitativo de Hume, a pesar de que ninguno habría logrado dar una respuesta satisfactoria de la paradoja ficcionalista del peculiar simbolismo que sus propias propuestas originaron, cuando sin pretenderlo pasaron a simbolizar respectivamente la estética del clasicismo y del romanticismo (Koebner, Meder, 2006);

7. Finalmente, se comprueba la presencia de este triple tipo de artificios ilusionistas, miméticos y simbolista en el humor y en la propia vida, a pesar de ser dos tipos de actividades aparentemente marginales al arte (Zangwill, 2007).

Para concluir tres reflexiones críticas. Según Levinson, la naturaleza ficcional de las imágenes virtuales exige que sean objeto de una autentica contemplación artística capaz de apreciar los peculiares artificios ilusionistas, miméticos y simbolistas que la hacen posible, ya se refiera al arte figurativo clásico, a la realidad virtual o al arte no-figurativo posterior (Blair, 2007). Sin embargo aquí surgen diversos interrogante: ¿Logró la realidad virtual mediática o el arte no-figurativo posterior a 1950, localizar de presencia de otros artificios artísticos aún más básicos que los usados por el arte clásico, al menos según Wittgenstein y Gombrich, sin necesidad de tener que ser objeto de un artificio claramente manipulador, como postuló Heidegger respecto del 'aparecer de un resplandor'? (Darvas, 2007). ¿No se podría justificar la distinción entre la obra de arte y el artefacto o realidad virtual en virtud de otro tipo de prepuestos existenciales inherentes a este otro tipo de artificios artísticos, como recientemente Paskow ha criticado a Levinson? (Paskow, 2004). Finalmente, ¿Se puede seguir hablando de una paradoja del ficcionalismo artístico cuando el tipo de realidad virtual o el arte posterior a 1950, ya no se sigue rigiendo mediante el mismo tipo de artificios ilusionistas que el arte figurativo anterior? (Kraut, 2007). 


\section{Crowther, 2007: el transignificado contextual de las imágenes mediáticas}

Paul Crowther en 2007 ha tratado de dar respuesta positiva a la situación paradójica en que se encuentra la realidad virtual, a consecuencia de la crisis acaecida en el arte contemporáneo posterior a 1950, a fin de valorar el alcance contextual de las propias creaciones artísticas, en Definiendo el arte, creando el canon (Crowther, 2007). En su opinión, con posterioridad a 1950 se habrían perdido los criterios normativos mínimos para valorar la peculiar creatividad innovadora no-figurativa de la realidad virtual y del propio arte contemporáneo. Es más en su opinión, cualquier pretensión por rehabilitar un canon de este tipo se vería obligada a imponer un estilo artístico excluyente, donde no tendrían cabida los cánones usados por otras culturas, teniendo que ser tachada de "eurocéntrica" (Phillips, 2007). Además, por otro lado, hoy día también se comprueba como la academia y el público en general habrían demostrado una asombrosa maleabilidad para adaptarse a esta actual ausencia de criterios valorativos a la hora de valorar dicho tipo de realidades virtuales, dando lugar a la subsiguiente dispersión de tendencias muy extremas donde parece que al final "todo vale" (Spencer, 2007). Se constata así el nacimiento de una nueva era desconstructiva como la actual, donde todo son "dudas" acerca de la realidad virtual, la noción de arte y de los valores canónicos que a su vez deberían juzgar la creatividad artística y virtual, sin tampoco disponer de una alternativa capaz de resolverlas (Esteban, 2007).

De todos modos Paul Crowther cree que esta conclusión tan negativa se podría haber evitado, si se llevara a cabo una recuperación de la teoría mimética del arte y de la propia realidad virtual como aproximación de la naturaleza, siempre que a su vez cumpla una condición sobreañadida (Puelles Romero, Fernández Gómez, eds., 2008): abandonar definitivamente su anterior pretensión de concebir la figuración y el virtuosismo como simple correspondencia mimética, para sustituirla a su vez por un nueva forma de imitación estilizada, donde se tuviera en cuenta el peculiar canon artístico normativo que en cada caso se utiliza, ya sea en el caso de la obra de arte o de una simple realidad virtual. Sólo así se podría redefinir la noción de arte y de realidad virtual, atribuyéndoles una capacidad mimética de reproducción intencional de imágenes estilizadas o simplemente virtuales, así como la capacidad de localizar los valores canónicos normativos desde los cuales se deberían juzgar el peculiar estilo o el virtuosismo en cada caso propuesto (Sharpe, 2008).

De este modo se espera superar una interpretación meramente social del origen de la obra de arte y de la realidad virtual correspondiente, al modo como ahora habría defendido Kendal Walton, siempre que se reconozcan otros dos rasgos superpuestos de la imagen artística o virtual (Eagleton, 2006): por un lado, el carácter manifiestamente ambivalente de los peculiares artificios ilusionistas usados en cada caso, ya sean la ley de la figura y del fondo, del simbolismo o del respectivo juego de lenguaje, ya se les pretenda dar un alcance figurativo o no figurativo. En efecto, en el seguimiento imitativo de los ulteriores procesos de estilización de un canon artístico siempre puede predominar el punto de vista del objeto o del espectador, al modo señalado por Gombrich y Wollheim, o anteriormente por el artificio ilusionista wittgensteiniano de la doble figura pato-conejo (Tilghman, 2005). Sin embargo siempre cabe, por otro lado, la posibilidad de hacer un uso conceptual o simbólico más diversificado del anterior artificio ilusionista, en razón de los distintos juegos de lenguaje que a su vez permitirían justificar la aparición de las anteriores ambivalencias o reverberaciones 
entre los distintos posibles sentidos otorgados a las imágenes artísticas, al modo también fue sugerido por Nelson Goodman (Godie, 2007).

En cualquier caso ahora se considera que la noción de estilo permitirían justificar las variaciones formales ocurridas en el modo de concebir los distintos tipos de artificio ilusionistas usados por la creatividad artística y por la teoría de la imagen a lo largo de la historia, sin por ello tener que volver a una interpretación historicista de los estilos y épocas artísticas, al modo como ocurrió en la estética de Hegel, al menos según Gombrich (Garber, 2008). A este respecto ahora también se hace notar como Kant anticipó algunos de los criterios estéticos que después serían utilizados por la teoría del arte y por la teoría de la imagen del siglo XX para resolver sus propias paradojas y sin sentidos (Russo, 2005). En efecto, según Crowther, el arte contemporáneo y la teoría de la imagen posterior a 1950 habrían vuelto a la separación que ya Kant habría establecido entre la estética de la belleza natural (por ejemplo, respecto de la sensación) y aquellos otros efectos miméticos e ilusionistas intencionalmente buscados por la creatividad artística y virtual (Baricco, 2008). Por su parte la noción de estilo artístico permitiría justificar el mayor o menor alcance que las distintas especialidades y tendencias de la creatividad artística y virtual atribuyen a estos mismos artificios ilusionistas (Urbina, 2008).

De este modo el arte contemporáneo y la teoría de la imagen podrían seguir justificando una ilimitada capacidad de transformación de los objetos inicialmente vulgares para dar lugar a auténticas obras de arte, o a una realidad virtual cada vez más sofisticada, con tal de aportar una previa justificación del peculiar canon normativo y del artificio ilusionista usado en cada caso por el respectivo estilo artístico (Altshuler, 2005). Por su parte los artificios ilusionistas usados a la hora de recrear este tipo de realidades virtuales permitirían justificar la aparición de una duplicidad de figuras, con la consiguiente reverberación de sentido, haciendo posible el tránsito desde lo vulgar a lo artístico, o a lo simplemente virtual, como de hecho ocurre en el arte contemporáneo y en las propias imágenes mediáticas, sin tener ya que atribuir esta capacidad de transfiguración a una mera reflexibilidad de tipo filosófico, al modo propuesto hoy día por Arthur Danton. En cualquier caso se dan tres pasos para alcanzar estas conclusiones (Messori, 2007):

a) Se analizan los dos problemas generados a su vez a la hora de concebir el arte como un tipo de realidad virtual ( Rubia del Prado, 2006): 1) La posible exclusión cultural eurocéntrica de aquellos estilos artísticos procedentes de otros ámbitos no occidentales, donde ya no se aceptaría este modo de concebir la realidad virtual, salvo que se introduzca una noción más amplia y pertinente del arte, como ahora se propone; 2) La defensa de un canon normativo compatible con esta nueva definición de arte y de realidad virtual, sin fomentar por ello un relativismo cada vez más banal respecto de los valores normativos por los que se debe juzgar la propia creatividad artística (Nelson, Zeckhauser, 2008).

b) Se rechaza la pretensión occidental de condicionar la creatividad artística a la previa fijación de un estilo respecto de la apropiada reproducción de una realidad virtual, dando lugar a su vez a dos problemas (Marchán, 2005): 3) La justificación dada por Kant en su teoría del juicio estético sobre un posible paso desde la belleza natural a la belleza artística, siempre que se disponga de un artificio ilusionista apropiado, sin atribuirlo al mero capricho, como con frecuencia ocurre en el arte contemporáneo (Ismael, 2007); 4) El reconocimiento de la finalidad y del valor reverberante atribuido a una imagen artística en razón de la previa fijación del estilo artístico, siguiendo a su vez criterios profesionales propios de cada espe- 
cialidad creativa, sin que ya esta valoración se pueda dejar en manos de un juicio reflexivo de tipo especulativo o filosófico (Nehamas, 2007).

c) Finalmente, se analizan los diversos tipos de artificio ilusionista que a su vez hacen posible la aparición de los diversos estilos creativos, ya sea de carácter artístico o meramente virtual, a saber: 5) El desdoblamiento o el reverberar del sentido, característico de la imaginación y del arte pictórico; en estos casos se asigna a la imagen pictórica o virtual una clara intencionalidad creativa a fin de poder lograr un doble tipo de figuración, sin que en ningún caso ese doble efecto intencionalmente causado sea casual (Kieran, 2006); 6) El desdoblamiento o peculiar solapamiento que la metáfora literaria establece entre el lenguaje y la percepción del objeto correspondiente, introduciendo una separación entre el uso literal de las palabras y el significado expresivo que en cada caso se les asigna, dando lugar también a un doble efecto reverberante intencionalmente buscado; 7) El peculiar desdoblamiento que también se produce entre el sonido de las notas musicales individualmente consideradas y la armonía musical resultante, buscando a su vez un contraste intencional entre el doble efecto reverberante que cada una de ellas origina (Prinz, 2006); 8) Se comprueba así como cada estilo introduce una peculiar articulación entre el estilo, la imagen y los artificios ilusionistas en cada caso usados, ya sea para extender su poder reverberante, para detenerlo o comprimirlo, con la consiguiente connotación de un momento epocal muy preciso, como especialmente sucede con la proyectiva arquitectónica, aunque algo similar también se podría decir de la música o de la pintura (Tadday, 2007).

Para concluir, una reflexión crítica. Crowther generaliza para todo tipo de especialidades artísticas y tratamientos de la imagen los artificios de tipo ilusionista que Gombrich había descrito solo para la pintura. Por su parte también pretende devolver al canon artístico normativo un protagonismo que sin duda había perdido en el arte contemporáneo y en la teoría de la imagen posterior a 1950 (Mauthner, 2008). Para justificar esta doble pretensión se atribuye a los distintos estilos artísticos la virtualidad de articular el doble significado generado a su vez por el específico reverberar del sentido de los distintos artificios ilusionistas, así como por la previa fijación del canon normativo utilizado en cada caso. Sin embargo es precisamente es aquí precisamente donde surge la polémica (Mahne, 2007): ¿Hasta qué punto los distintos estilos y tendencias artísticas del arte contemporáneo y de la teoría de la imagen hacen gala de una dispersión creciente sin que quepa esperar una convergencia hacia una recategorización de la doble función mimética y a la vez ilusionista tradicionalmente asignada al canon y a los estilos artísticos, cuando son precisamente dichas nociones las que hoy día se ponen más en tela de juicio? ¿Hasta que punto en el arte contemporáneo y la teoría de la imagen posterior a 1950 sólo habría cambiado los estilos, manteniendo inalterable el uso antes dado a los artificios miméticos e ilusionistas, o no son más bien estos últimos los que verdaderamente han cambiado, al descubrir en ellos virtualidades reflexivas y autorreferenciales que anteriormente no se habían tenido en cuenta? (Washburn, 2007).

\section{Seel, 2007: el poder reverberante de la escenificación mediática}

Martin Seel en 2007, en La fuerza de la aparición (Seel, 2007), ha prolongado algunas consideraciones sobre la creatividad artística que el mismo ya había defendido anteriormente en Estética de la aparición (Seel, 2000). En aquella ocasión caracterizó la experiencia artística en razón de la inicial aparición de una forma peculiar de iluminación estética, capaz de mirar con ojos de contemporaneidad las experiencias epocales más diversas, una vez redu- 
cidas a su aspecto meramente fenoménico, al modo como con anterioridad también habrían señalado Kant, Hegel, Nietzsche, Heidegger o Adorno, entre otros. A este respecto la estética de la aparición le habría permitido justificar un rasgo prototípico inherente a la manifestación fenoménica de cualquier imagen estética, a saber (Russo, 2006): su capacidad de reflejar en un instante dado la actualidad epocal vigente, mediante el concurso de un artificio artístico elemental, como ahora sucede con el tintineo de la luz o con el ruido de fondo, que serían a su vez capaces de reflejar la dependencia que los acontecimientos artísticos mantienen a su vez respecto del momento epocal en el que suceden. Hasta el punto que ahora se debería otorgar una prioridad a este artificio elemental, ya se haga un uso artístico o virtual, sobre el indudable influjo que simultáneamente también pueden ejercer otros posibles artificios secundarios, como serían los artificios de tipo figurativo, simbólico o meramente ornamental, característicos del arte clásico, al modo señalado por Arthur Danton, o aún antes por Ernst Gombrich y Nelson Goodman*.

En cualquier caso, en esta reciente publicación de 2008, La fuerza de la aparición, se da un paso más, destacando tres principios interpretativos básicos que, desde Kant hasta Adorno, habrían caracterizado a la fundamentación dialéctica del arte contemporáneo y de la teoría de la imagen, a saber: a) la prioridad que el contexto epocal ejerce sobre el contenido estético concreto otorgado en cada caso a una imagen artística; b) el condicionamiento que el trasfondo perceptivo ejerce a su vez sobre el ulterior significado concreto otorgado a una determinada figura; c) la posible alteración que puede experimentar un determinado simbolismo en virtud del juego del lenguaje desde el que se interpreta (Romero de Solís, D.; López Lloret, J.; Murcia Serrano, 2007). Posteriormente, una vez justificados estos tres principios, ahora también se aborda un problema anteriormente dejado sin resolver, a saber: determinar el artificio estético elemental que a su vez permite atribuir a una imagen artística una determinada la fuerza o magia expresiva para referirse a la actualidad vigente de un determinado contexto epocal, como ahora va a suceder con la performance o puesta en escena así como con los consiguientes procesos de estilización a los que se va a someter dicha imagen artística (Wettstein, 2005). Además, ahora se pretende aplicar este mismo artificio estético elemental a todo tipo de imágenes creativas, ya sean artísticas o virtuales, sin admitir que por este motivo haya que establecer una ruptura entre ellas (Blaas-Pratscher, 2006).

1. Teoría, recategoriza los distintos artificios artísticos utilizados por las imágenes creativas, ya sean estéticas o virtuales, para articular el tiempo y el espacio. Se muestra así como la aparición de una imagen artística o virtual dependen a su vez de distintos procesos de escenificación cada vez más estilizados (Spaemann), a los que se le asigna una virtualidad muy singular: su capacidad de expresar la actualidad vigente de un determinado contexto epocal, en virtud del peculiar modo de organizar el tiempo o el espacio por parte de las correspondientes imágenes estéticas (Saito, 2007). Precisamente se atribuye a Nietzsche el haber llevado a cabo una marginación esteticista de la anterior concepción ontológica clásica del ser, para sustituirla por la fuerza creciente con que la escenificación cada vez más estilizada de unas imágenes creativas, ya sean estéticas o virtual, podrían a su vez expresar la actualidad epocal de un estilo artístico efectivamente vigente. Evidentemente una estética evolutiva de este tipo genera ventajas y desventajas indudables, pero también da lugar a procesos de intensificación y de distanciamiento crítico respecto de estas nuevas formas de aparición estética y de sus corres- 
pondientes formas de articular el tiempo y el espacio, que una teoría dialéctica del arte y de la imagen debe tener en cuenta (Zamir, 2007).

2. Artes, comprueba como la escenificación ha sido a lo largo de la historia el artificio estético básico de las sucesivas virtualidades otorgadas a la aparición de una imagen creativa, ya tenga una finalidad estética o virtual, sin que ello haya impedido su progresiva estilización, como ahora se comprueba que ha sucedido en el caso de la literatura, la arquitectura, el cine y la música (Ott, 2005). En todos estos casos se comprueba como la capacidad de las imágenes estéticas y virtuales de hacer presente la actualidadvigente de un determinado contexto epocal ha sido a su vez compatible con el recurso a distintos estilos artísticos y tecnológicos cada vez más sofisticados (Yeazell, 2005), como al menos sucede en cuatro casos paradigmáticos: 1) el recurso literario a una lengua escrita, en el caso de Platón; 2) la organización por parte de la arquitectura de distintos espacios dentro de un único espacio compartido, que a su vez se interacciona con el respectivo entorno paisajístico (Maderuelo, 2005); 3) la posibilidad de concebir la imagen filmica de un doble modo: como una mera descripción de la actualidad vigente o como si se tratara de una forma de evasión de esa misma realidad, recurriendo en cada caso a distintos artificios artísticos de tipo mimético o ilusionista, como de hecho ahora también sucede en la interpretación realista o antirrealista del séptimo arte (Walkerdine, 2007); 4) finalmente, la transformación del automóvil en una sala de concierto musical cada vez más sofisticada, mostrando a su vez como la vida cotidiana no está reñida con la calidad artística, con independencia de las innegables transformaciones culturales a las que este hecho puede dar lugar en el modo de concebir la música (Stock, 2007).

3. Crítica, analiza un conjunto de obras de arte muy curiosas, donde se pone de manifiesto como la progresiva estilización de los artificios de escenificación pueden acabar transformando el modo de concebir una obra de arte (Brown, 2006). Se analizan así las relaciones existentes entre la racionalidad y el humor en la obra teatral Corrección (de errores) de Thomas Bernhard. O las ironías sobre la contemplación en el relato, Mi año en una bahía solitaria, de Peter Handkes. O el elogio del laconismo en El error del copista de Botho Strauss. O la ley cómica antiterror usada con profusión por Christoph Schlingesief. O el suspense de las sombras filmicas en la cinematografía de Fassbinder. O la duplicidad de sentidos en las fotografías naturalistas y a la vez artísticas de Jürgen Wiesners. O la vigente actualidad del pasado en la obra monumental de Matthias Holländers (Guyer, 2005).

Para concluir, una reflexión crítica. Martin Seel muestra como la escenificación y la estilización permiten mostrar las relaciones de contemporaneidad que una imagen artística mantiene a su vez con el respectivo contexto epocal donde tiene lugar. Para lograrlo desdobla su anterior artificio básico elemental, según predomine el punto de vista del objeto o del espectador, sin tener que recurrir ya solamente al consabido artificio tintineo de la luz todos estos casos luz o al ruido de fondo (Tabakowska, 2007). Sin embargo cabe seguir planteándose. ¿Realmente la estilización de una escenificación es independiente de los demás artificios de tipo figurativo, simbólico u ornamental, característicos del arte clásico, o están todos ellos recíprocamente interaccionados entre sí? (Mosebach, 2005). Verdaderamente ahora Martin Seel no acaba de responder específicamente a esta pregunta, aunque a su vez hace una propuesta muy sugerente. En realidad la progresiva estilización de una escenificación no es un artificio estético superpuesto a los demás, sino que más bien pretenden ser el presupuesto implícito 
que está sobreentendido en la puesta en ejercicio de todos los demás artificios, determinando su sentido y haciéndolos a su vez posibles (Dodd, 2007). De todos modos convendría advertir que en ningún caso, ni la puesta en escena o escenificación, ni la ulterior estilización de este mismo artificio, puede pretender sobreponerse y suplantar la necesidad de una adecuada figuración, de un simbolismo o de una adecuada ornamentación, como en ocasiones ha ocurrido en la fundamentación dialéctica de la teoría del arte y de la teoría de la imagen. En efecto, sin estilo no hay escenificación, aunque $\sin$ figuración, simbolismo u ornamentación tampoco hay estilo, ya se trate del arte clásico, del moderno o del contemporáneo (Koebner, 2008).

\section{Conclusión: ¿se puede evaluar la excelencia e innovación de una imagen?}

Evidentemente los autores ahora analizados han puesto de manifiesto los criterios usados por la teoría del arte y las tecnologías de la información para valorar la dimensión genéticoretroductiva, simbólica, contextual, o simplemente escénica de las representaciones mediáticas, resaltando a este respecto su capacidad informativa, transfiguradora, transignificativa o simplemente reverberante (Rieger, 2005). En muchos casos estos criterios de valoración proceden de la teoría del arte, según los distintos estilos artísticos hicieran un uso más o menos sofisticado de las múltiples virtualidades que ahora ofrece la imagen visual. De todos modos estos criterios tuvieron una gran utilidad a la hora de fijar los criterios de excelencia e innovación creativa por parte de la teoría de la imagen y de las tecnologías de la comunicación (Davies, 2007). Evidentemente los autores ahora analizados no siempre aplican los mismos criterios, aunque en general se puede decir que se da un proceso escalonado de profundización en la valoración que en cada caso se hace de estos criterios de excelencia e innovación. De todos modos analizar la articulación de todos estos criterios es un tema muy complejo, especialmente en el ámbito de las tecnologías de la comunicación, que tendrá que ser analizado en otro lugar (Strohner, 2006). 


\section{Referencias}

Altshuler, B. (ed.) (2005). Collecting the New. Museums and Contemporary Art, Princeton University, Princeton.

Ameriks, K.; Stolzenberg, J. (Hrsg.) (2007). Ästhetic und Philosophie, Aesthetics and Philosophy, Internationales Jahrbuch des Deutschen Idealismus, Walter De Gruyter, Berlin.

Baecker, D. (2005). Form und Formen der Kommunikation, Suhrkamp, Frankfurt.

Baricco, A. (2008). Los bárbaros. Ensayo sobre la mutación, Anagrama, Barcelona.

Barthes, R. (2007). El Imperio de los signos, Seix Barral, Barcelona.

Becker, R.; Orth, E. W. (Hrsg.) (2005). Medien und Kultur. Mediale Weltauffassung, Königshausen und Neumann, Würzburg.

Blaas-Pratscher, C. et al. (2006). Offentliche Kunst, Kunst im öffentlichen Raum, Springer, Wien.

Blair, S. (2007). Harlen Crossroads. Black Writers and the Photograph in the Twentieth Century, Princeton University, Princeton.

Bollini, F. (2007). Estetica analitica 1-2, Studi di estetica, III Serie, XXXI, Clueb.

Brown, S.; Volgsten, U. (2006). Music and Manipulation. On the Social Uses and Social Control of Music, Berghahm, New York.

Budd, M. (2008). Aesthetic Essays, Oxford University, Oxford.

Crowther, Paul (2007). Defining Art, Creating the Canon. Artistic Value in an Era of Doubt, Clarendon, Oxford University, Oxford.

Darvas, G. (2007). Symmetry. Cultural-historical and Ontological Aspects of Science-arts Relations.

The Natural and Man-made World in an interdisciplinary Approach, Birkhauser, Basel.

Davies, S. (2007). Philosophical Perspectives on Art, Oxford University, Oxford.

Dodd, J. (2007). Works of Music. An Essay in Ontology, Clarendon, Oxford University, Oxford.

Eisentein, S. M. (2006). Jenseits der Einstellung. Schriften zur Filmtheorie; Lenz, F.; Diederichs, H.

H. (Hg.); Suhrkamp, Frankfurt.

Eagleton, T. (2006). La estética como ideología, Trotta, Madrid.

Esteban, I.; El efecto Guggenheim. Del espacio basura al ornamento, Anagrama, Barcelona, 2007.

Everaert-Desmedt, N. (2006). Interpréter l'art contemporain: la sémiotique peircienne appliquée aux oeuvres de Magritte, Klein, Duras Wenders, Chávez, Parant et Corillon, De Boeck Université, Bruxelles.

Farber, D. (eds.) (2007). What they Think of US. International Perceptions of the United States since 9/11, Princeton University, Princeton.

Garber, M. (2008). Patronizing the Arts, Princeton University, Princeton.

Gaut, B. (2007). Art, Emotions and Ethics, Oxford University, Oxford.

Gibson, J. (2007). Fiction and the Weave of Life, Oxford University, Oxford.

Godie, P.; Schelleckens, E. (ed.) (2007). Philosophy and Conceptual Art, Clarendon, Oxford University, Oxford.

Gower, K. K. (2007). Public Relations and the Press. The Troubled Embrance, Northwestern University, Evanston (IL).

Graham, G. (2007). The Re-enchantment of the World. Art versus Religion, Oxford University, Oxford.

Green, M. S. (2007). Self-Expression, Oxford University, Oxford.

Guyer, P. (2005). Values of Beauty. Historical Essays in Aesthetics, Cambridge University, Cambridge. Ismael, J. T. (2007). The Situated Self, Oxford University, Oxford.

Jäger, Ernst (2006). Filmkritiker, Lewinski, H. (Hrsg.), Film \& Schrift, B: 2, Text + Kritik, Müchen.

Kieran, M. (2006). Revealing Art, Routledge, Abingdon.

Kivy, P. (2007). Music, Language, and Cognition. And Other Essays in the Aesthetics of Music, Oxford University, Oxford.

Koebner, T. (Hg.) (2008). Ästhetische Existenz - Ethische Existenz. Ein zeitgenössisches EntwederOder?, Text + Kritik, München.

Koebner, T.; Meder, T. (Hrsg.) (2006). Bildtheorie und Film, Text und Kritik, München, 2006. 
Koselleck, R. Begriffsgeschichten, Suhrkamp, Frankfurt.

Kraut, R. (2007). Artworld Metaphysics, Oxford University, Oxford.

Kulvicki, J. V. (2006). On Images. Their Structure and Content, Clarendon, Oxford University, Oxford. Lackey, J.; Sosa, E. (2006). The Epistemology of Testimony, Clarendon, Oxford University, Oxford. Levinson, Jerrold (2006). Conteplating Art. Essays in Aesthetics, Oxford University, Oxford. Maderuelo, J. (2005). El paisaje. Génesis de un concepto, Abada, Madrid.

Mahne, N. (2007). Transmediale Erzähltheorie. Eine Einführung, Vandenhoeck \& Ruprecht, Göttingen. Marchán, S. (2005); Real-Virtual en la estética y la teoría de las artes, Paidós, Barcelona.

Mauthner, F. (2008). La maledizione della parola, Bertolini, L. (ed.); Aesthetica Supplementa 22, Centro Internazionale Studidi Estetica, Palermo, Septiembre.

Messori, R. (2007). Dire l'esperienza estetica, Aesthetica 80, Parma,.

Mosebach, M. (2005). Du sollst dir ein Bild machen. Über alte und neue Meister, Klampen, Spring.

Nehamas, A. (2007). Only a Promise of Happiness. The Place of Beauty in a World of Art, Princeton University, Princeton.

Nelson, J. K.; Zeckhauser, R. J. (2008). The Patron's Payoff. Conspicuous Commissions in Italian Renaissance Art, Princeton University, Princeton (NJ).

O'Callaghan, C. (2007). Sounds. A Philosophical Theory, Oxford University, Oxford.

Ott, M. (2005). U. A. Hollywood. Phatasma / Symbolische Ordnung in Zeiten des Blockbuster-Films, Text + Kritik, München.

Paskow, Alan (2004). The Paradoxes of Art. A Phenomenological Investigation, Cambridge University, Cambridge.

Phillips, A. (2007). Multiculturalism without Culture, Princeton University, Princeton (NJ).

Prinz, J. J. (2006). Gut Reactions. A Perceptual Theory of Emotion, Oxford University, Oxford.

Puelles Romero, L.; Fernández Gómez, R. (eds.) (2008). Estetización y nuevas artes, Suplemento 13, Contrastes, Universidad de Málaga, Málaga.

Rieger, S. (2005). Die Ästhetik des Menchen. Über das Technische in Leben und Kunst, Suhrkamp, Frankfurt.

Romero de Solís, D.; López Lloret, J.; Murcia Serrano, I. (2007). Variaciones sobre el color, Universidad de Sevilla, Sevilla.

Rubia del Prado, L. La (2006). Dalí: excéntrico concéntrico, EUG - Universidad de Granada, Granada.

Russo, L. (ed) (2005); Jean-Baptiste Du Bos e l'estetica dello spettatore, Centro Internationale Studi di Estetica, Palermo.

- (ed.) (2006), Attraverso l'imagine. In ricordo di Cesare Brandi, Suplementa 19, Aestetica, Palerm.

Saito, Y. (2007). Everyday Aesthetic, Oxford University, Oxford.

Scheeler, C. (2006). Across Media, National Gallery Art, Washington, California University, Berkeley. Seel, Martin (2007). Die Macht des Erscheinens, Suhrkamp, Frankfurt.

- (2000); Ästhetikk des Erscheinens, Suhrkamp, Frankfurt.

Seel, G. (2006). End of Art-Endings in Art. La fin de l'art-Les fins dans les arts. Ende der Kunst - Enden in der Kunst, Schwabe, Basel.

Sharpe, W. C. (2008). New York Nocturne. The City After Dark in Literature, Painting, and Photography, Princeton University, Princeton.

Spencer, D. R. (2007). The Yellow Journalism. The Press and America's Emergence as a World Power, Northwestern University, Evanston (IL).

Speranza, G. (2006). Fuera de campo. Literatura y arte argentinos después de Duchamp, Anagrama, Barcelona.

Spivey, N. (2006). Wie Kunst die Welt erschuf, Philip Reclam, Stuttgart.

Stock, K. (ed.) (2007). Philosophies on Music. Experience, Meaning, and Work, Oxford University, Oxford.

Strohner, H. (2006). Kommunikation. Kognitiven Grundlagen und praktische Anwendungen, Vandenhoeck und Ruprech, Götingen.

Tabakowska, E.; Ljunberg, C.; Fischer, O. (2007). Insistent Images, John Benjamins, Amsterdam. 
Tadday, U. (Hrsg.) (2007). Musikphilosophie, Musik-Konzepte, Text + Kritik, München, XI. Taylor, Barry (2006). Models, Truth, and Realism, Clarendon, Oxford University, Oxford.

Tilghman, B. R. (2005). Pero, ¿es esto arte? El valor del arte y la tentación de la teoría, Universidad, Valencia.

Urbina, P. A. (2008). Filocalía o amor a la belleza, Rialp, Madrid.

Varnedoe, Kirk (2006). Pictures of Nothing. Abstract art since Pollock, Princeton University Press, Princeton.

Walkerdine, V. (2007). Children, Gender, Video Games. Forwards a Relational Approach to Multimedia, Palgrave, New York.

Washburn, P. S. (2007) The African American Newspaper. Voice of Freedom, Northwestern University, Evanston (IL).

Wettstein, H. (2005). The Magic Prism. An Essay in the Philosophy of Language, Oxford University. Wiesing, Lambert (2006). Artfizielle Präsenz. Studien zur Philosophie des Bildes, Suhrkamp, Frankfurt.

Wollaeger, M. (2007). Modernism, Media, and Propaganda. British Narrative from 1900 to 1945, Princeton University, Princeton.

Yeazell, R. B. (2007). Dutch Painting and the Realist Novel, Princeton University, Princeton.

Zamir, T. (2007). Double Vision. Moral Philosophy and Shakespeare Drama, Princeton University, Princeton (NJ).

Zangwill, N. (2007). Aesthetic Creation, Oxford University, Oxford.

\section{Sobre el Autor}

Dr Carlos Ortiz de Landázuri: Universidad de Navarra, España 